\title{
Effects of the Contact Geometry on High Strain Rate Behavior of Woven Graphite/Epoxy Composites
}

\author{
Fatih Turan \\ Mechanical Engineering Department, Istanbul University, Istanbul, Turkey \\ E-mail: fatihturan@istanbul.edu.tr \\ Mohammad R. Allazadeh \\ Institute of Mechanical Engineering, University of Pannonia \\ Veszprem, Hungary, H-8200 \\ E-mail: mrallazadeh@yahoo.com \\ Sylvanus N. Wosu \\ Mechanical Engineering and Materials Science Department, University of Pittsburgh \\ Pittsburgh PA, 15261, USA \\ E-mail: snn2@pitt.edu
}

Received: September 19, 2011

Accepted: October 8, 2011 Published: January 1, 2012

doi:10.5539/jmsr.v1n1p107

URL: http://dx.doi.org/10.5539/jmsr.v1n1p107

\begin{abstract}
Effects of the contact geometry on high strain rate failure behavior of woven graphite/epoxy composites are presented. Compressive split Hopkinson pressure bar was used for high strain rate experiments. Woven graphite/epoxy composites were loaded transversely using two different contact geometries at the impact energies of $67 \mathrm{~J}$ and $163 \mathrm{~J}$. It is observed that smaller contact area gives higher damage, resulting in higher energy absorption, elastic modulus and strain rate and peak stress in the specimens.
\end{abstract}

Keywords: High strain rate, Split Hopkinson pressure bar, Absorbed energy, Impact load, Woven graphite epoxy composite, Contact geometry

\section{Introduction}

Composite materials have been widely used in many applications in which high strength to weight ratio is required such as aircraft structures, space shuttles, armored vehicles, and automobiles (Daniel \& Ishai, 1994). In some cases such as automobile accidents, bird strikes on aircraft structures, and ballistic impact loading on armored vehicles, these composites are exposed to high strain rate loading and therefore it is vital to understand the effect of the loading direction on high strain rate behavior of woven graphite/epoxy composites.

The widely used technique for the determination of high strain rate behavior of composites is split Hopkinson pressure bar apparatus which works based on one dimensional wave propagation theory in elastic bars. Split Hopkinson pressure bar is also known as Kolksy bar whose inventor is Kolksy. Wosu et al. (2006) and Ojo et al. (2007) modified split Hopkinson pressure bar bar in order to study penetration and perforation mechanics of composite plates at high strain rates. Wosu concluded that strain rate, ultimate strain and energy absorption increase with increasing perforation energy. Ojoet al. $(2007,2003)$ used the split Hopkinson pressure bar with different penetrators to find the threshold energy for three different thicknesses of woven composites. They found out that cracks propagate in thinner specimens faster than in thicker ones and the damage mechanism depend on the size and geometry of penetrator.

Woldenbet and Winson (1997) conducted research to understand the effect of specimen geometry and the effect of varying lengths to diameter ratio of graphite/epoxy laminates at high strain rate. The results indicated that there is no significant influence of geometry and length to diameter ratio. 
A comprehensive study has been done by Wosu et al. (2003) to understand the high strain rate behavior of woven carbon composite materials fabricated by low cost vacuum assisted resin infusion molding (VARIM) processusing compression split Hopkinson pressure bar at high strain rates ranging from $320 \mathrm{~s}^{-1}$ to $1149 \mathrm{~s}^{-1}$. In this study, high strain rate behavior of stitched and unstitched woven carbon/epoxy composites have been studied in plane and off plane directions $\left(0^{\circ}-45^{\circ}\right.$ degree for plain weave and $0^{\circ}-90^{\circ}$ degree for satin weave at $15^{\circ}$ degree increments). The results show that the peak stress and modulus tend to increase with increasing strain rate for woven composites while unstitched composites exhibit higher peak stress and modulus than stitched ones. The study also reveals that satin weave composites display higher peak stress and modulus when compared to plain weave composites and the samples loaded along off axes angles exhibit a large nonlinear response increasing up to $45^{\circ}$. This study enables one to compare low cost woven composite materials produced Vacuum assisted resin infusion molding (VARIM) process with those produced by traditional high cost woven composites in terms of dynamic compressive behavior and to see the high strain behavior of stitched composites.

Hsiao et al. (1999) carried out a research to study the strain rate effects on the transverse compressive and shear behavior of 72- and 48-ply unidirectional carbon/epoxy composites at strain rates up to $1800 \mathrm{~s}^{-1}$ using split Hopkinson pressure bar. The results indicated that transverse compressive strength increases with increasing strain rate even though ultimate strain exhibits no strain rate effect. The stress strain curve stiffens as the strain rate increases until it becomes almost linear at the strain rate of $1800 \mathrm{~s}^{-1}$ in transverse direction. In addition, thirty and forty-five degree off axis compression tests showed that shear stress - strain behavior exhibits high nonlinearity as the strain rate increases.

Naik and Venkateswara (2008) concluded that compressive strength and failure strain increase with increasing strain rate in thickness directions compared with those along warp and fill directions while compressive modulus is lower along thickness directions compared with those along warp and fill directions. Hall and Guden (2001) carried out research to determine the mechanical properties and failure mechanisms of unidirectional reinforced graphite/epoxy composites using a compression split Hopkinson pressure bar. The results showed that there is a strong rate dependency on the strength properties in the transverse direction although no similar dependence is observed longitudinally.

However, the effect of the contact geometry on the high strain ratebehavior of transversely loaded woven graphite composites has not been observed yet. Thus, the objective of the present study is to determine the effect of contact geometry on the high strain rate behavior of transversely loaded woven graphite/epoxy composites.

\section{Experimental Technique}

\subsection{Material Selection}

The composite materials used in this study are graphite/epoxy composites and fabricated by VARIM process using plain weave $\mathrm{T} 300 \mathrm{~B}-40 \mathrm{~B}-3 \mathrm{~K}$ - Toray carbon fabric and $\mathrm{SC}-14$ epoxy resin as a matrix material. The thicknesses of the composite materials are 8 ply $(2 \mathrm{~mm})$ and 12 ply $(3 \mathrm{~mm})$ with a diameter of $25.4 \mathrm{~mm}$. Figure 1 shows the schematic of plain weave composite (Elleithy, 2000).

VARIM are gaining acceptance for applications such as armored vehicles, aerospace structures, naval/marine, and automobile structures in which production of large scale structures with a low cost is required (Wosu et al., 2003). Goren and Atas (2008) described the VARIM method as following; dry pre-form fabrics are placed an open mould and a plastic vacuum bag is placed on the top of the mould. The one - sided mould is connected with a resin source (epoxy) and a vacuum pump. The liquid epoxy infuses into the reinforcing carbon fibers thanks to the vacuum drawn through the mould. Curing and demoulding steps follow the impregnation process to finish the product.

\subsection{Split Hopkinson Pressure Bar}

A split Hopkinson pressure bar was used for high strain rate testing (Nwosu, 1995). The compression Hopkinson bar apparatus consists of incident, transmitter, and striker bars (300 Maraging AMS 6514 steel). The incident and transmitter bars are $3.66 \mathrm{~m}$ in length and the striker bar is $0.61 \mathrm{~m}$ in length while all bars are $0.0254 \mathrm{~m}$ in diameter. Also a retracting rod attached to the striker bar is used to pull back the striker bar to desired ram length then the striker bar has a kinetic energy according to that ram length. During the test, the specimen is sandwiched between the incident and transmitted bars.Typical setup of split Hopkinson pressure bar is shown schematically in Figure 2.

When the striker bar hits the incident bar, a compressive stress/strain pulse is produced on the impact end of the incident bar. This compressive pulse traveling through the incident bar reflects at the free surface as a tensile pulse and returns to the impact face. Thus, the pulse in the incident pressure bar is twice the length of the striker 
bar. This pulse (incident pulse) travels through the incident bar toward the incident bar - specimen interface and is recorded by the strain gage located in the midpoint of the incident bar after 395 microseconds. The incident pulse reaches the interface of the incident bar and specimen at $790 \mu$ s where some portion of it is reflected back to the incident bar as a tensile (reflected) pulse and some portionis transmitted to the transmitter bar as a compressive pulse. It should be noted that the reflected pulse starts a little earlier than the transmitted pulse. This short delaying time occurs due to the finite thickness of the specimen. During the period of stress wave propagation through the specimen, the specimen undergoes deformation until its dynamic limit is reached. The relative magnitudes of these pulses depend on the physical properties of the specimen. The properties of the bar materials such as density, bar wave velocity, and diameter and the specimen dimensions are known prior to the data analysis from a SHPB test. From the signals obtained by the strain gages and using one dimensional wave propagation theory, the analytical relations to calculate strain, strain rate, and stress as a function of time in the specimen in split Hopkinson pressure bar testing can be calculated,respectively, as next(Allazadeh \& Wosu Sylvanus, 2011, pp:311-325),

$$
\begin{gathered}
\varepsilon_{s}(t)=-\frac{2 C_{0}}{L_{0}} \int_{0}^{t}\left[\varepsilon_{r}(t)\right] d t \\
\dot{\varepsilon}_{S}(t)=-\frac{2 C_{0}}{L_{0}} \varepsilon_{r}(t) \\
\sigma_{s}(t)=\frac{A_{b} E_{0} \varepsilon_{t}(t)}{A_{s}}
\end{gathered}
$$

where $C_{o}$ is the elastic wave velocity in the bars, $L_{o}$ is the specimen initial length, $A_{b}$ is the cross sectional area of the bars, $\mathrm{A}_{\mathrm{s}}$ cross sectional area of the specimen, the Young's modulus of the bars, $\varepsilon_{t}$ is the transmitted strain pulse, $\varepsilon_{\mathrm{r}}$ is the reflected strain pulse, and $\mathrm{t}$ is the time duration.

\subsection{Loading Configuration}

Typical loading configurations for specimens loaded with using smaller indentor and without using smaller indentor are shown in Figures 3 and 4, respectively.

Using different contact area in the incident bar does not affect the equation for the stress in the specimen (3) due to the equilibrium assumptions in the system as shown below.From the equilibrium assumption in the specimen, following equation can be obtained as

$$
\begin{gathered}
F_{1}=\left(\sigma_{i}+\sigma_{r}\right) A_{b^{\prime}}=\left(\sigma_{t}\right) A_{b}=F_{2}, \\
\left(\sigma_{i}+\sigma_{r}\right)=\frac{A_{b}}{A_{b^{\prime}}}\left(\sigma_{t}\right)
\end{gathered}
$$

where $F_{1}$ and $F_{2}$ are the forces each side of the specimen, $\sigma_{i}$ is the incident stress pulse, $\sigma_{r}$ is the reflected stress pulse, $\sigma_{t}$ is the transmitted stress pulse $A_{b}$ and $A_{b^{\prime}}$ are the contact areas of the transmitted bar and the smallerindentor with the specimen, respectively.The average stress in the specimen from equation,

$$
\sigma_{s}=\frac{\left(\sigma_{i}+\sigma_{r}\right) A_{b^{\prime}}+\left(\sigma_{t}\right) A_{b}}{2 A_{s}}
$$

Substituting equation (5) into (6), the average stress in the specimen can be expressed as

$$
\sigma_{s}=\frac{A_{b}\left(\sigma_{t}\right)}{A_{s}}
$$

\subsection{System Calibration}

The purpose of the system calibration is to obtain a relationship between the compressed pressure applied to the system and the striker velocity delivered to the incident bar and the energy transferred to the incident bar using infrared photo gate detectors just before the impact.

A photo gate detector and a flag with the length of $0.023 \mathrm{~m}$ were used to measure the duration of the blocking time in photo gate detectors. The time measured in photo gate detectors is divided to the length of the flags to determine the velocity. The photo gate detector was positioned to the end of the impact bar to measure the impact velocity $V_{i}$ just before impact. In order to measure the impact bar velocity, the flag was attached to the end of the striker rod. Once the pressure is applied, the rod with the flag moves toward the incident bar blocking 
the infrared beam in photo gate detectors just before the impact. The blocking time is obtained from a software program connected to the photo gate detectors (Data Studio). Then the blocking time is divided to the length of the flag to determine the impact bar velocity just before the impact. The impact energy transferred to the system is equal to the kinetic energy of the impact bar and can be expressed by

$$
E_{i}=\frac{1}{2} m_{s} V_{i}^{2}
$$

where $m_{s}$ is the mass of the striker bar. Finally, calibration curve can be obtained plotting striker velocity versus applied pressure and corresponding energy versus applied pressure data. Figure 5 gives the calibration curves showing there is a nonlinear relationship between the striker velocity and applied pressure.

\subsection{Energy measurements}

Assuming that the energy delivered by the incident bar and indentor is equal to the total expendable energy for the penetration process, the energy transferred by the propagating compressive wave to the composite plate is given by:

$$
E_{p}=\int_{0}^{t} F_{i}(t) d u_{n} \equiv E_{A}
$$

where $F_{i}(t)=A\left(\sigma_{i}(t)+\sigma_{r}(t)\right)$ is the net compressive loading force and the net plate displacement $\mathrm{du}_{\mathrm{n}}$ is

$$
d u_{n}(t)=\frac{\mathcal{c}_{0}}{E_{0}} \int_{0}^{t}\left[\sigma_{i}(t)-\sigma_{r}(r)-\sigma_{t}(t)\right] d t
$$

$E_{p}$ can be obtained as the integrated area of the force-displacement curve over the duration of the wave. Substituting $\mathrm{du}_{\mathrm{n}}$ expression from Equation (10) into (9), the net energy to be expended for the damage generation process plus energy losses to the fixture is expressed as(Allazadeh \& Wosu Sylvanus, 2011,STRAIN-January):

$$
\begin{aligned}
& E_{A}=\left(\frac{A c_{0}}{E_{0}}\right) \int_{0}^{t}\left[\sigma_{i}(t)^{2}-\sigma_{r}(t)^{2}-\sigma_{t}(t)^{2}\right] d t \\
& E_{A}{ }^{\min }=\Delta E_{a b s} \\
& E_{A}{ }^{\max }=\Delta E_{a b s}+\Delta E_{s}
\end{aligned}
$$

Thus, Equation (11) gives the total energy absorption curve decomposed into energy absorbed by the plate $\left(\Delta E_{a b s}\right)$ and the elastic strain energy $\left(\Delta E_{s}\right)$. The numerical integration is carried out with all time shifted to zero and all three waves beginning at the same time and for the same time duration, $t$. This is justified by placing the strain gages at mid-point of the incident and transmitted bars at the same distance from the specimen.

\section{Results and Discussion}

\subsection{Effect of the Contact Geometry on the Energy Absorbed}

Figures 6 and 7 show the effect of contact geometry on the energy absorbed at the same impact energies for 8 ply and 12 ply specimens, respectively. There is a significant difference in energy-absorption curve after 200 microseconds indicating higher residual strain energy at higher incident impact energy for the smaller $(12.7 \mathrm{~mm})$ contact diameter. Figure 8 shows the peak energy absorbed at the same impact energies for 8 ply and 12 ply specimens showing that at high impact energy, a peak energy absorbed is higher for the $12.7 \mathrm{~mm}$ contact diameter than the $25.4 \mathrm{~mm}$. No significant difference at low impact energy below damage threshold. At the each impact energy, it is also observed that the specimens loaded with $12.7 \mathrm{~mm}$ indentor have a tendency to show reduction in the energy absorbed after the peak energy absorbed is reached while the specimens loaded without using indentor do not exhibit any significant reduction in the energy absorbed. This is because of the release of the strain energy stored during loading stage (Wosu et al., 2003) and this suggests that the plastic deformation of the specimens is higher when the indentor is used. Peak energy absorption and the energy retained by the specimen tend to be higher when the smaller contact area is used. This is expected because smaller contact area creates more energy in the specimen surface that causes more deformation in the specimen. It should be noted that the slope changes in the linear portion of the curve when the specimen is loaded using indentor. This is due to the fact that there is an impedance mismatch between indentor and the bars(Wosu et al., 2003). 


\subsection{Effect of the Contact Geometry on Stress - Strain Behavior}

Figures 9 and 10 show the effect of contact geometry on the stress - strain behavior at the same impact energies for 8 ply and 12 ply specimens, respectively. It is observed that the smaller contact area gives larger deformation to the specimens resulting in higher residual strain in the specimens and. The results also show characteristics of plastic failure as the strain curve did not return through the same path of loading. For the same incident energy, the materials fail at lower failure stress with small contact area than for a larger area.

Figure 11 and 12 show the effects of the contact geometry on peak stress and elastic modulus of transversely loaded 8 ply and 12 ply specimens, respectively. Smaller contact area gives slightly lower ultimate (peak) stress to failure. This can also be explained in terms of impedance mis-match between two dissimilar surfaces (Nwosu, 1995). The wave impedance is higher for the smaller contactarea relative to the specimen area. This will result in higher particle velocity, higher reflected wave amplitude, and lower amplitude of the transmitted wave, and therefore lower peak stress by Equation (6). Hence, peak stress for 8 ply specimen is higher than that of the 12 plyindicating a smaller stress to failure for the thinner sample. This means that ultimate peak stress is inversely proportional to the deformation level on the impacted surface due to the fact that the transmitted wave is lower when the higher deformation occurs in the specimen surface. This also results in lower elastic modulus when the smaller contact area is used in which higher deformation occurs.

\subsection{Effect of Contact Geometry on Strain Rate - Strain Behavior}

Figures 13 and 14 show the effect of contact geometry on the strain rate - strain behavior at the same impact energies for 8 ply and 12 ply specimen, respectively. It is clearly seen that smaller contact area gives higher deformation rate to the transversely loaded specimens since greater deformation and, consequently higher reflection occurs when the indentor is used. This result is expected as a consequence of the Equation (3) where the only parameter that may change the strain rate is reflected wave which depends on the deformation level. The greater the deformation level, the greater the reflected wave and lower transmitted wave.

\section{Summary and Conclusion}

High strain rate compression testing was carried out on transversely loaded specimens using two different contact geometries at two different impact energies. Following conclusions were drawn from the study.

(1) For the same applied energy, it is observed that the specimens loaded with $12.7 \mathrm{~mm}$ indentor have a tendency to show reduction in the energy absorbed after the peak energy absorbed while the specimens loaded without using indentor do not exhibit significant reduction in the energy absorbed.

(2) For the same applied impact energy, the smaller contact area gives larger deformation to the specimens and consequently the ultimate (peak) stress to failure is slightly lower for the specimens loaded with indentor. The smaller the contact area, the lower the dynamic elastic modulus for the specimens.

(3) For the same incident energy, the materials fail at lower failure stress with small contact area than for a larger contact area.

(4) For the same impact energy and same thickness, smaller contact area gives higher strain rate to the transversely loaded specimens because the effect of the compressive wave in the specimen's surface is higher due to the smaller area of the indentor.

For the future work, we plan to follow other techniques such as SEM technique to characterize the fracture surface morphology of impacted graphite/epoxy composites, RAMAN, etc. These techniques can help to understand and analyze the surface of materials.

\section{References}

Allazadeh M. R., \& Wosu Sylvanus N. (2011). High Strain Rate Compressive Tests on Woven Graphite Epoxy Composites. Applied Composite Materials, Volume 18, Number 4, pp: 311-325. http://dx.doi.org/10.1007/s10443-010-9159-6

Allazadeh M. R., \& Wosu Sylvanus N. (2011). High Strain Rate Compressive Tests on Wood. Strain, An international Journal for Experimental Mechanics, STRAIN-January. http://dx.doi.org/10.1111/j.1475-1305.2010.00802

Daniel, I. M., \& Ishai, O. (1994). Engineering mechanics of composite materials. New York, NY: Oxford University Press.

Elleithy, R. H. (2000). The hierarchical structure and flexure behavior of woven carbon fiber epoxy composite. Polymer Composites, 21, 716-723. http://dx.doi.org/10.1002/pc.10225 
Goren, A., \& Atas, C. (2008). Manufacturing of polymer matrix composites using vacuum assisted resin infusion molding. Archives of Materials Science and Engineering, 34, 117-120.

Hall, I. W., \& Guden, M. (2001). High strain rate testing of a unidirectionaly reinforced graphite/epoxy composite.Journal of Material Science Letters, 20, 897 - 899. http://dx.doi.org/10.1023/A:1010968514339

Hasio, H. M., Daniel, I. M., \& Cordes, R. D. (1999). Strain rate effects on the transverse compressive and shear behavior of unidirectional composites. Journal of Composite Materials, 33, 1620 - 1642. http://dx.doi.org/10.1177/002199839903301703

Naik, N. K., \& Venkateswara, R. K. (2008). High strain rate behavior of woven fabric composites under compressive loading. Materials Science and Engineering, A 474, 301 - 311 . http://dx.doi.org/10.1016/j.msea.2007.05.032

Nwosu S. N. (1995). High Performance Hopkinson Bar: Perforation Impact of Laminated Composite Plate.Wright Patterson AFB Special Report.

Ojo, O. B. (2003). Effect of penetrator configuration and size on the dynamic behavior of composite material under high strain rate loading. University of Pittsburgh, Department of Mechanical Engineering, Master Thesis.

Ojo, O. B., Wosu, S. N., Onipede D., \& Slaughter W. (2007). Effect of penetrator size on the dynamic failure response of woven graphite/epoxy composites around the critical perforation energy.J.ASTM International, 4, 189-197. http://dx.doi.org/10.1111/j.1475-1305.2010.00802.x

Woldenbert, E., \& Vinson, J.R. (1997). Effects of specimen geometry in high strain rate testing of graphite/epoxy composites. Structural Dynamic and Materials Conference Proceedings, Kissimmee,FL.

Wosu, S. N, Hosur, M. V, Jeelani, S., Vaidya, U. K., \& Ajit, D. K. (2003). Survivability of affordable aircraft composite structures. Air Force Final Report, Vol. 1.

Wosu, S. N., \& Hoy D. (2006). Digital imaging and fractographical analysis of perforation induced delamination of laminated graphite/epoxy composite. Journal of Composite Material, 14, 1577-1602. http://dx.doi.org/10.1177/0021998306060163

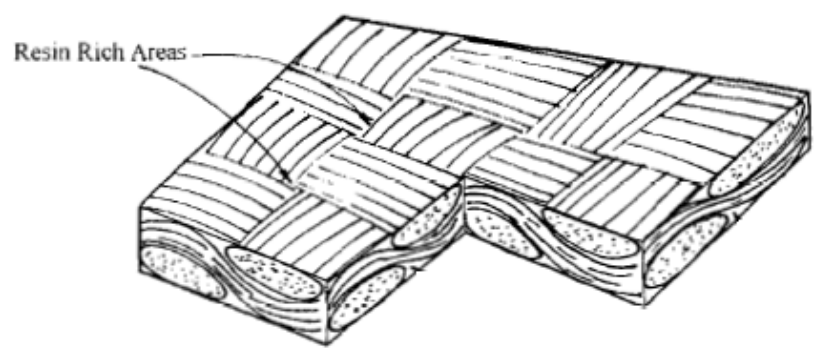

Figure 1. Schematic representation of the plain weave ply (Elleithy, 2000)

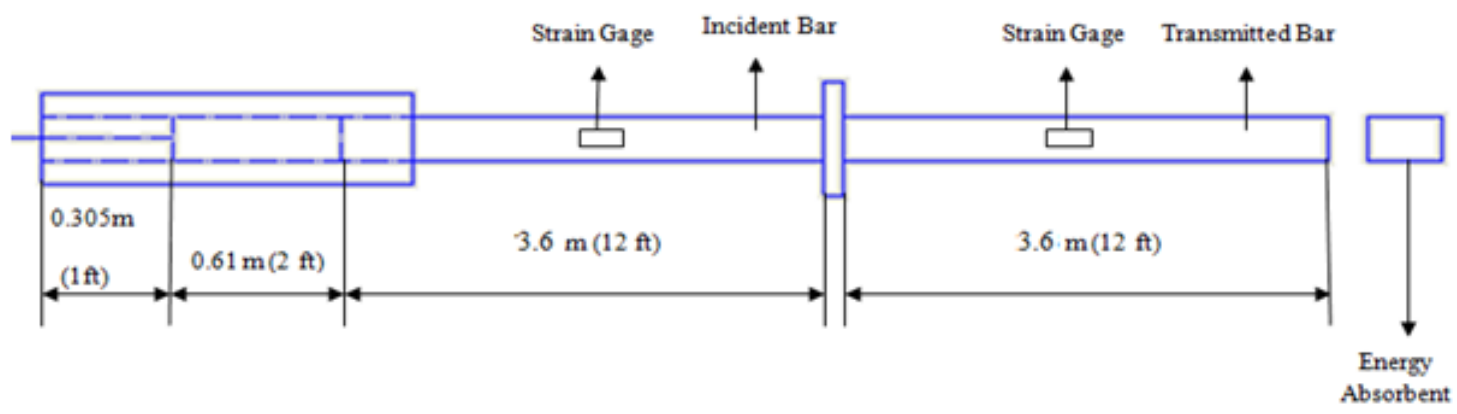

Figure 2. Schematic of the Hopkinson bar 


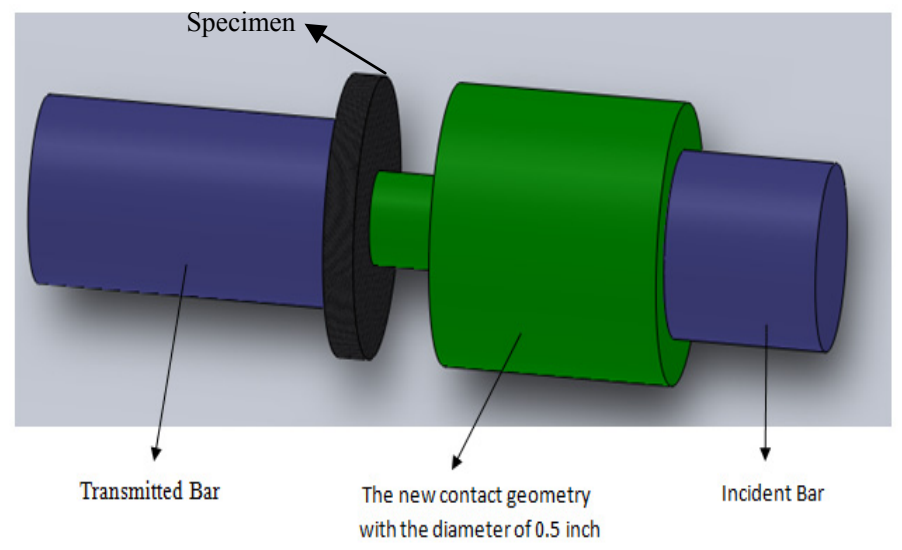

Figure 3. The schematic of the different contact geometry with the diameter of $1.3 \mathrm{~mm}$

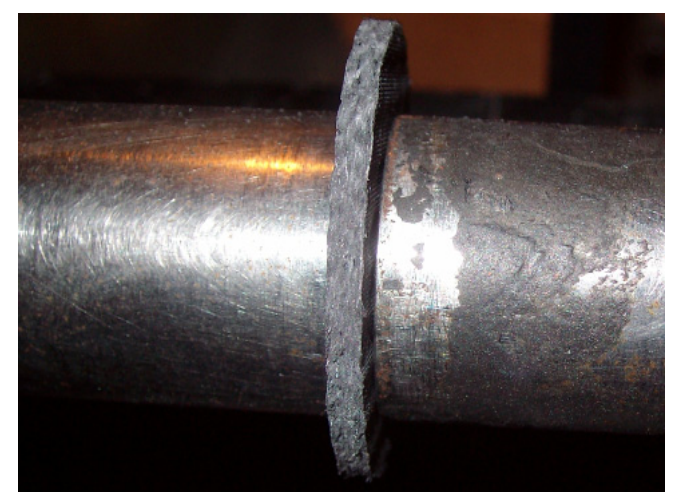

Figure 4. Transverse loading configuration without using smaller contact area

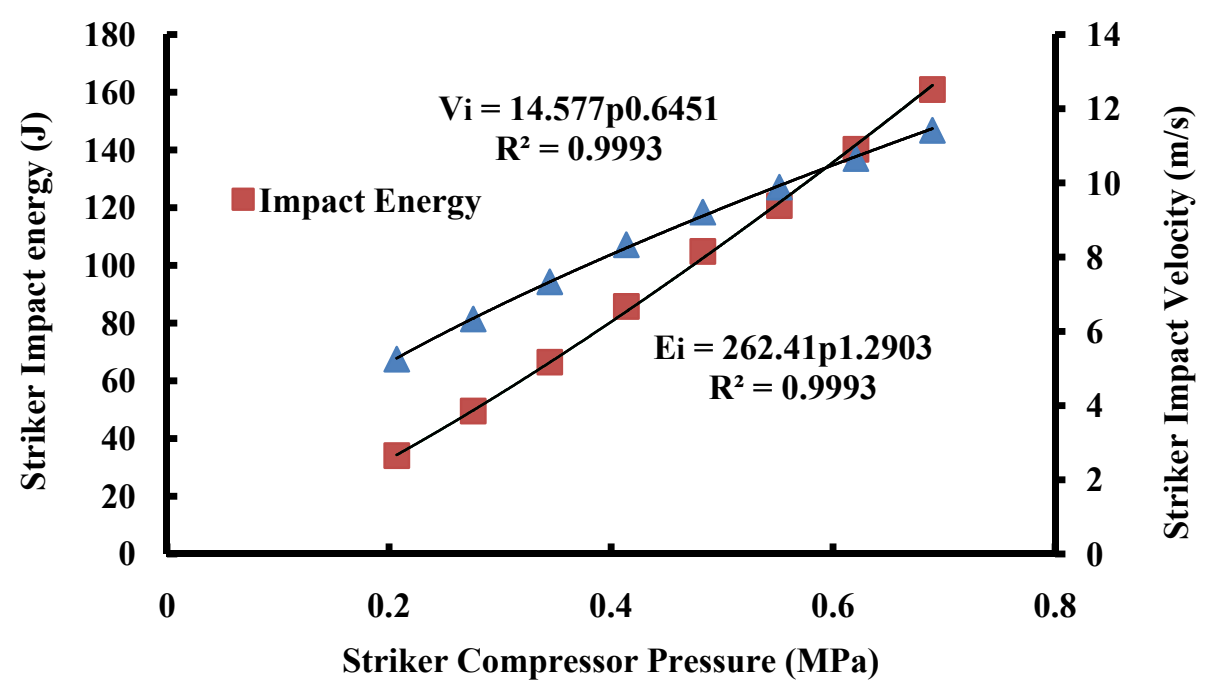

Figure 5. Relationship between the impact velocity, impact energy, and compressor pressure 


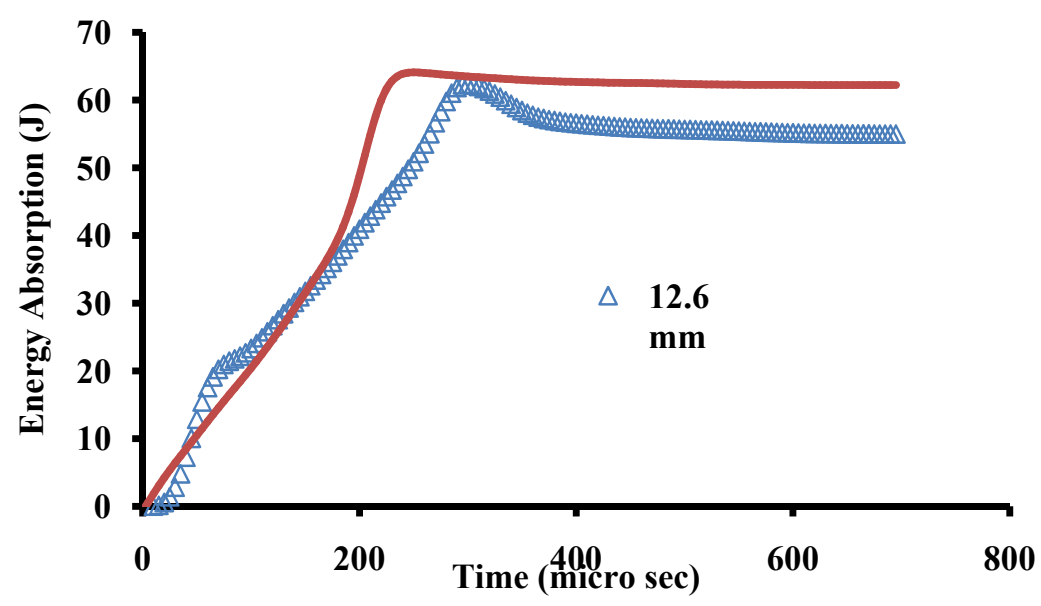

a)

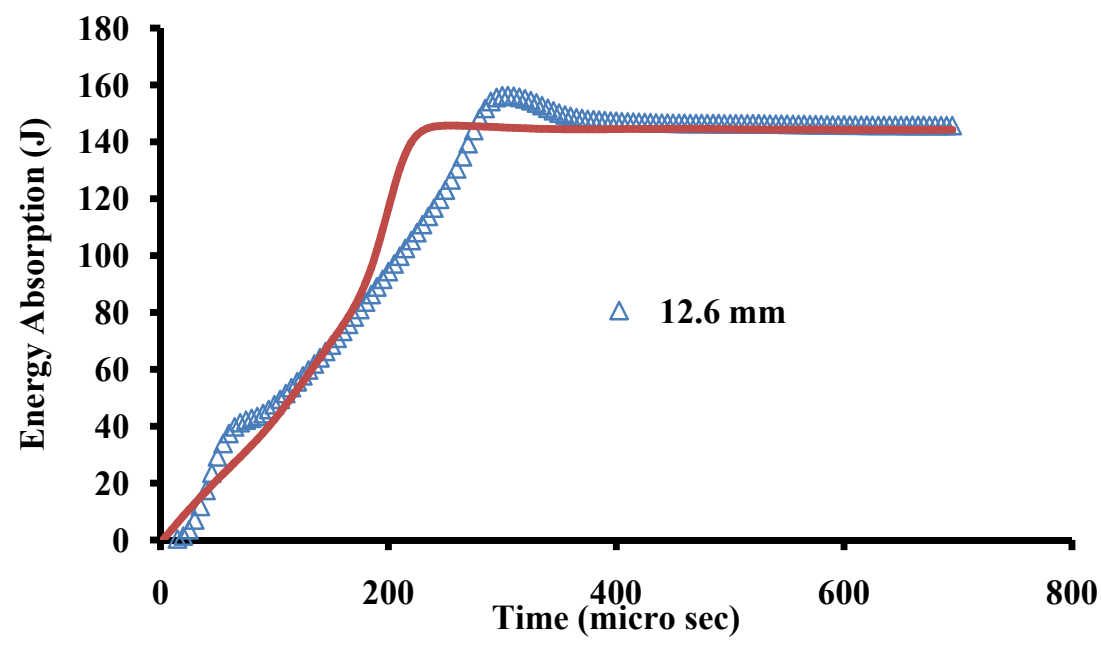

Figure 6. Effect of the contact geometry on the energy absorbed by transversely loaded 8 ply specimens (GW 8) with $12.7 \mathrm{~mm}$ and $25.4 \mathrm{~mm}$ diameterat the impact energies of a) $67 \mathrm{~J}$ and b) $163 \mathrm{~J}$ 

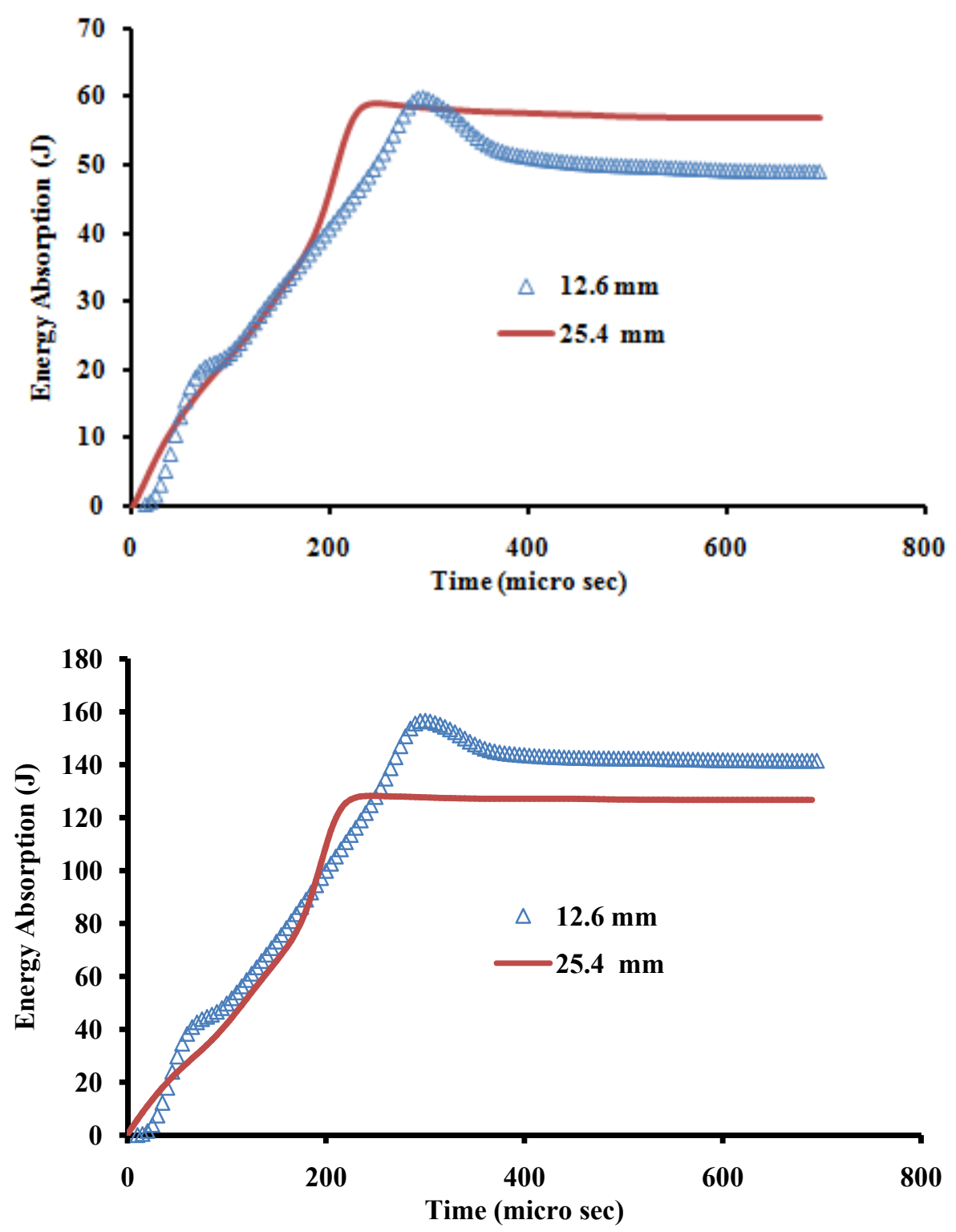

a)

Figure 7. Effect of the contact geometry on the energy absorbed by transversely loaded 12 ply specimens (GW 12) with $12.7 \mathrm{~mm}$ and $25.4 \mathrm{~mm}$ diameterat the impact energies of a) $67 \mathrm{~J}$ and b) $163 \mathrm{~J}$ 


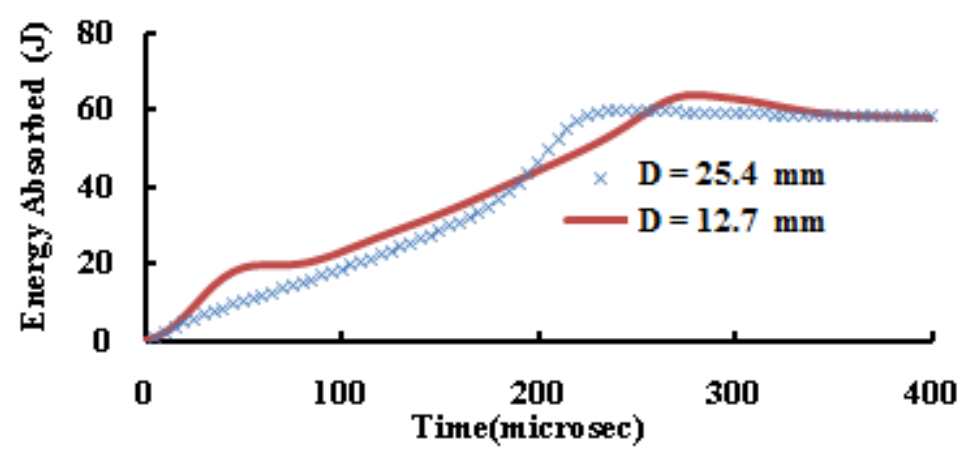

a)

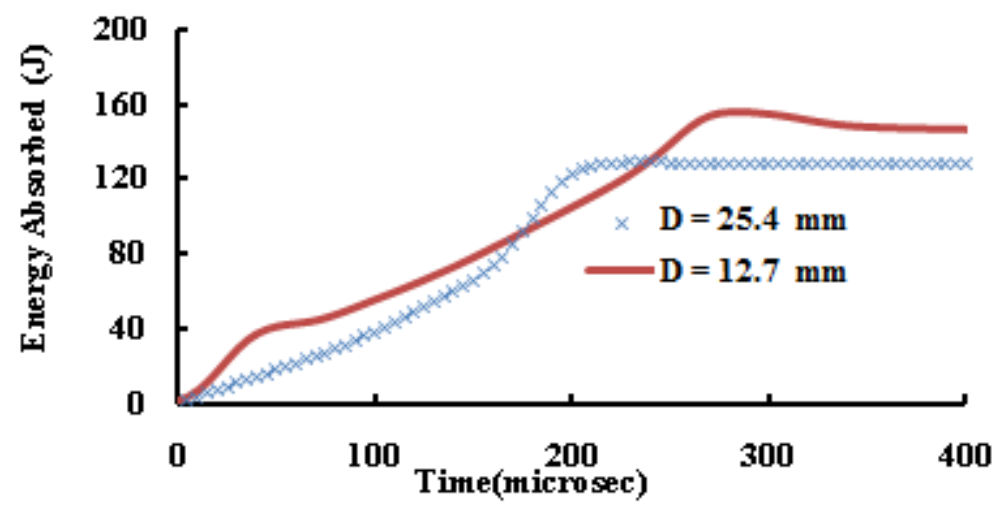

b)

Figure 8. Effect of the contact geometry on the peak energy absorbed with $12.7 \mathrm{~mm}$ and $25.4 \mathrm{~mm}$ diameter at same impact energies for a) GW 8 (8 ply) and b) GW 12 (12 ply) transversely loaded specimens 

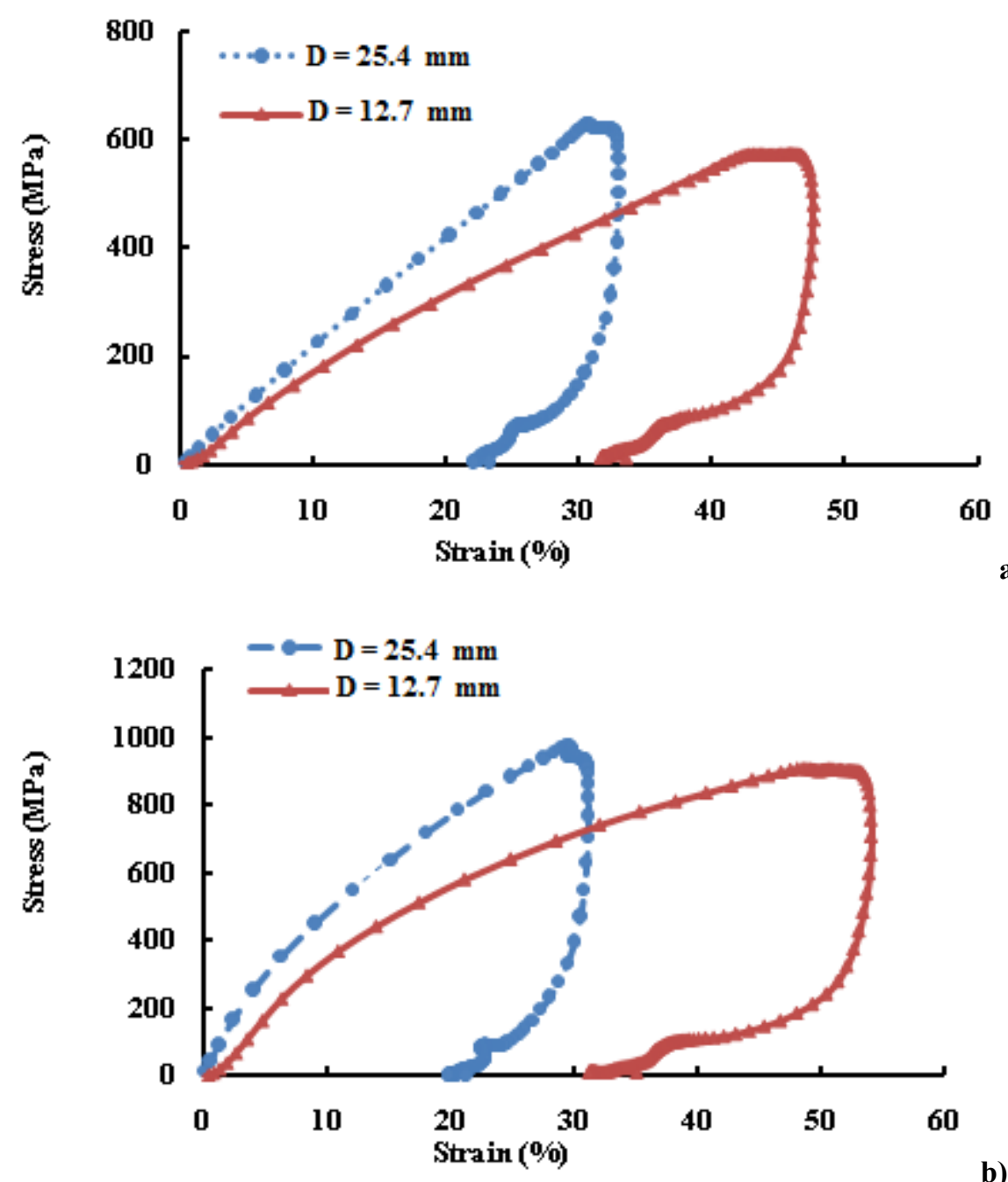

a)

b)

Figure 9. Effect of the contact geometry on the stress - strain behavior of transversely loaded 8 ply specimens (GW 8) with $12.7 \mathrm{~mm}$ and $25.4 \mathrm{~mm}$ diameter at the impact energies of a) $67 \mathrm{~J}$ and b) $163 \mathrm{~J}$ 

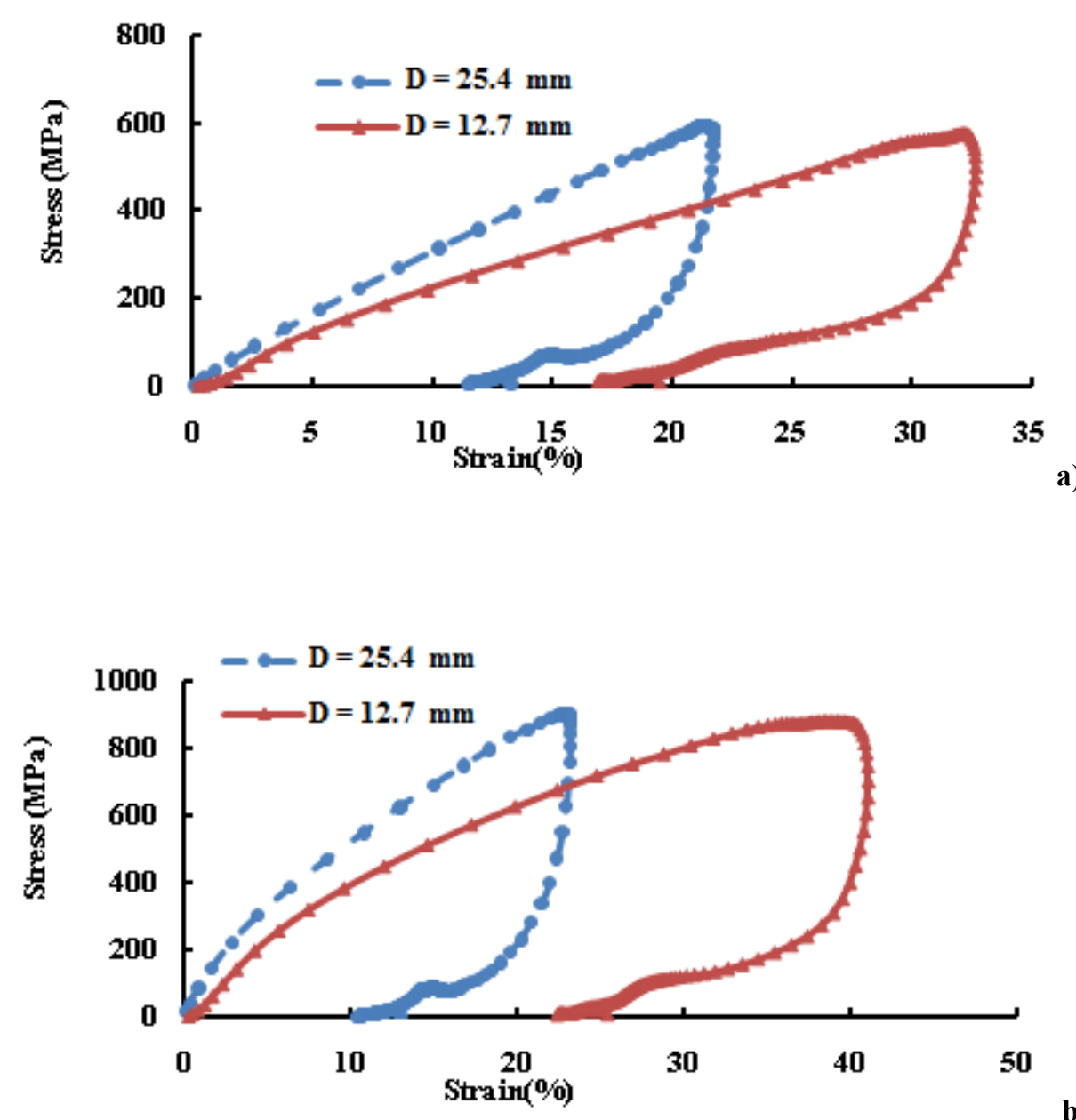

b)

Figure 10. Effect of the contact geometry on the stress - strain behavior of transversely loaded 12 ply specimens (GW 12) with $12.7 \mathrm{~mm}$ and $25.4 \mathrm{~mm}$ diameterat the impact energies of a) $67 \mathrm{~J}$ and b) $163 \mathrm{~J}$ 

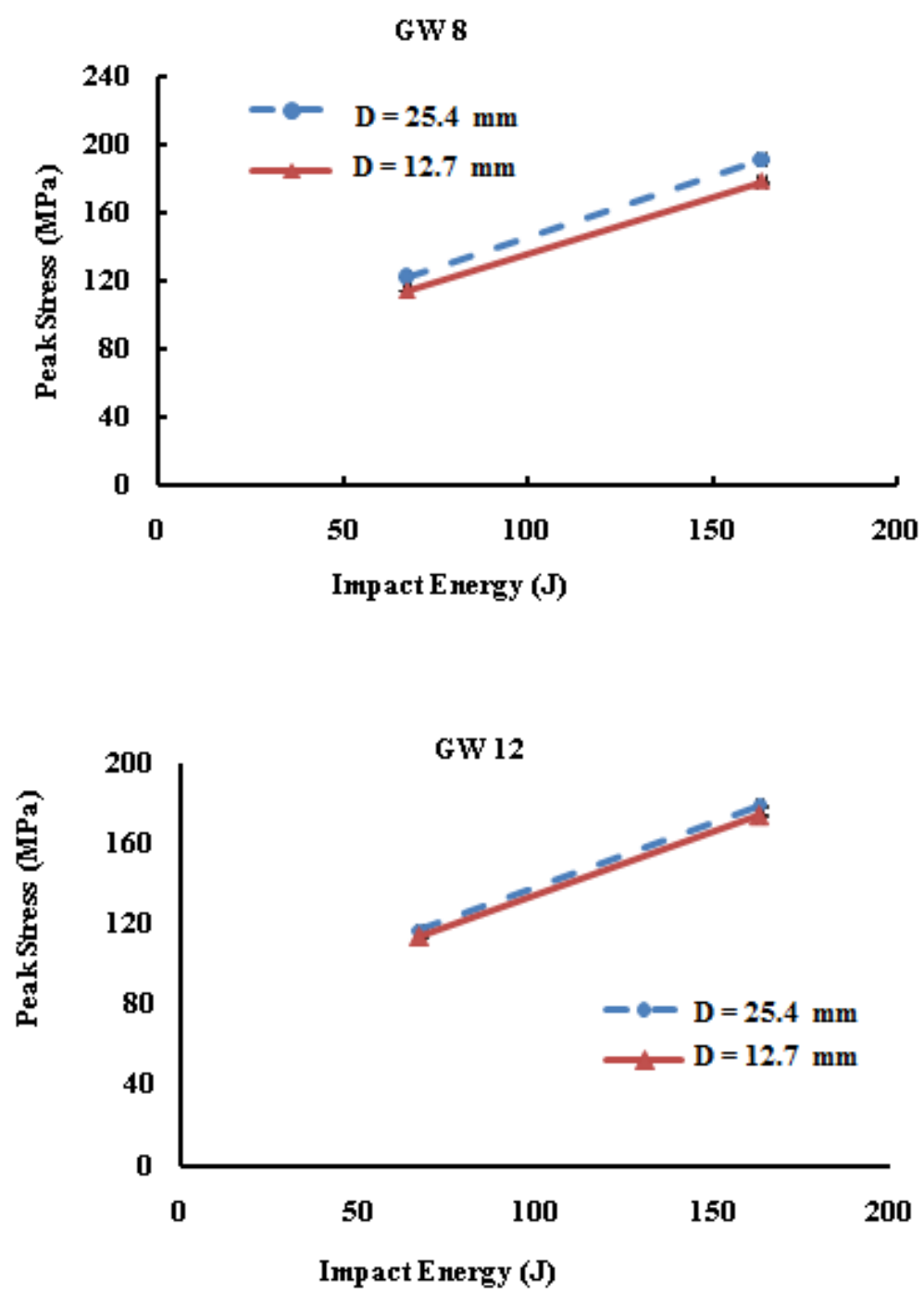

a)

Figure 11. Effect of the contact geometry on the peak stress at same impact energy for a) 8 ply and b) 12 ply specimens 


\section{GW 8}

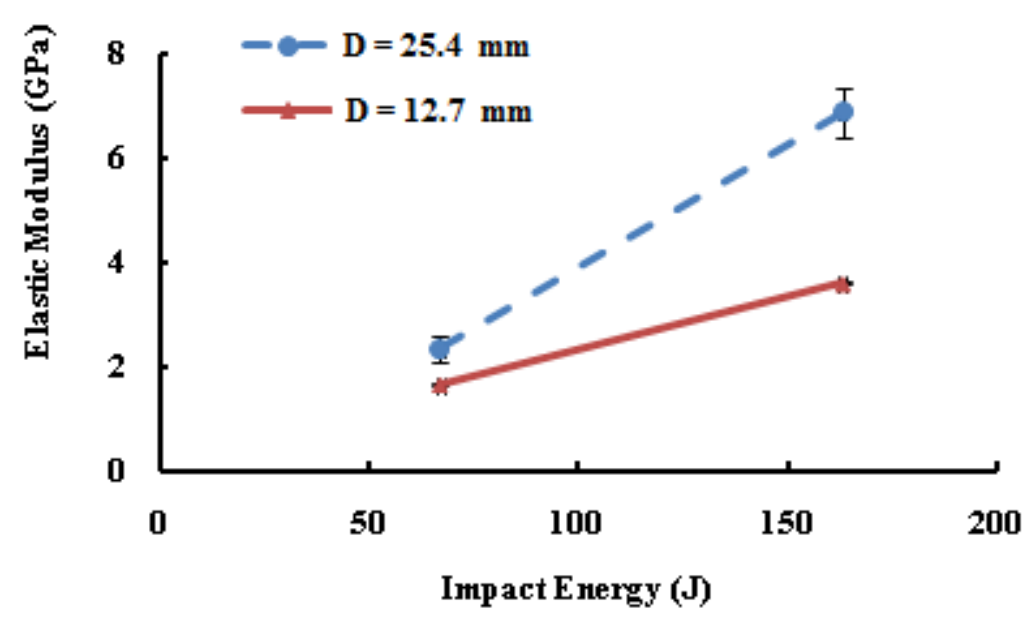

a)

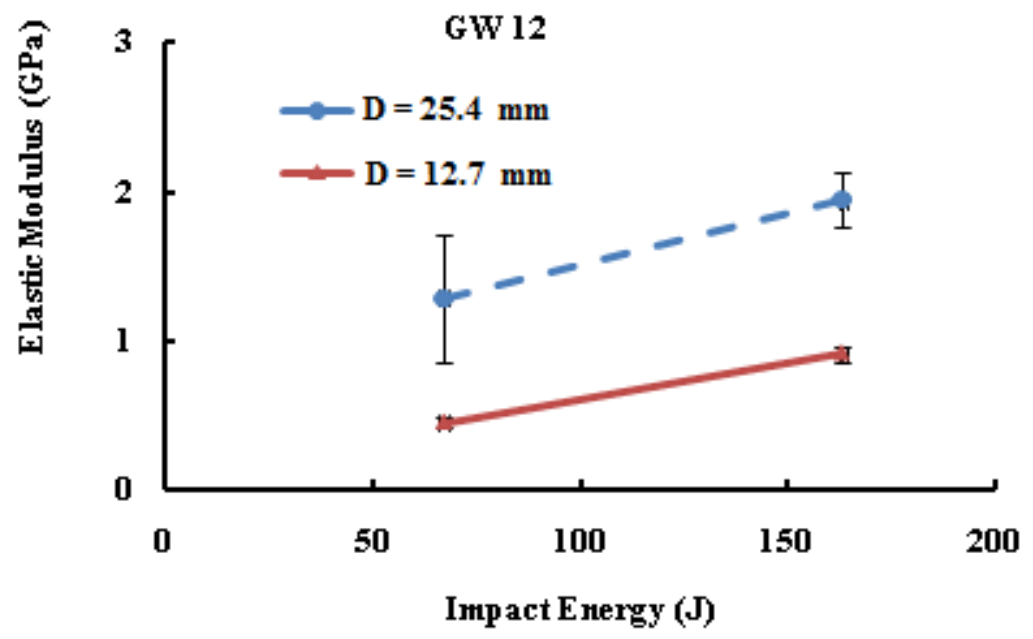

b)

Figure 12. Effect of the contact geometry on the elastic modulus of a) 8 ply (GW 8) and b) 12 ply (GW 12) transversely loaded specimens 


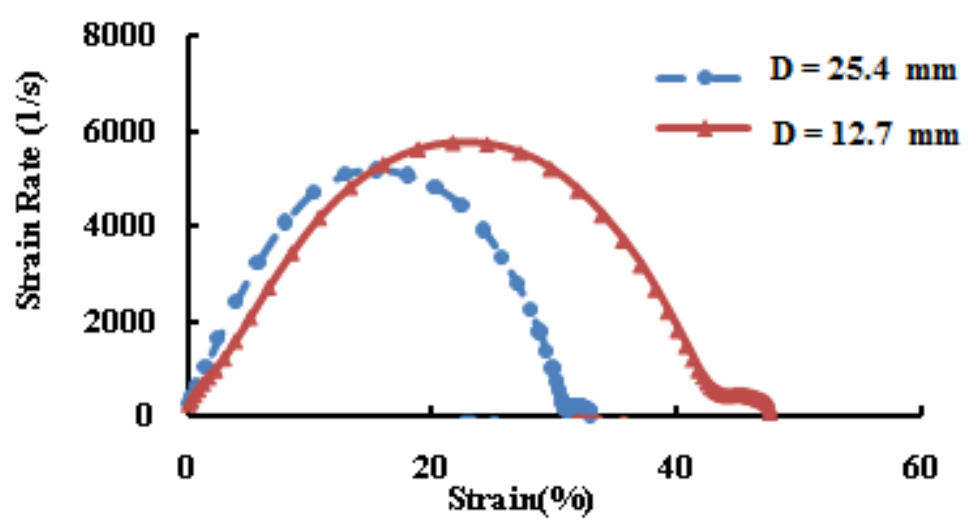

a)

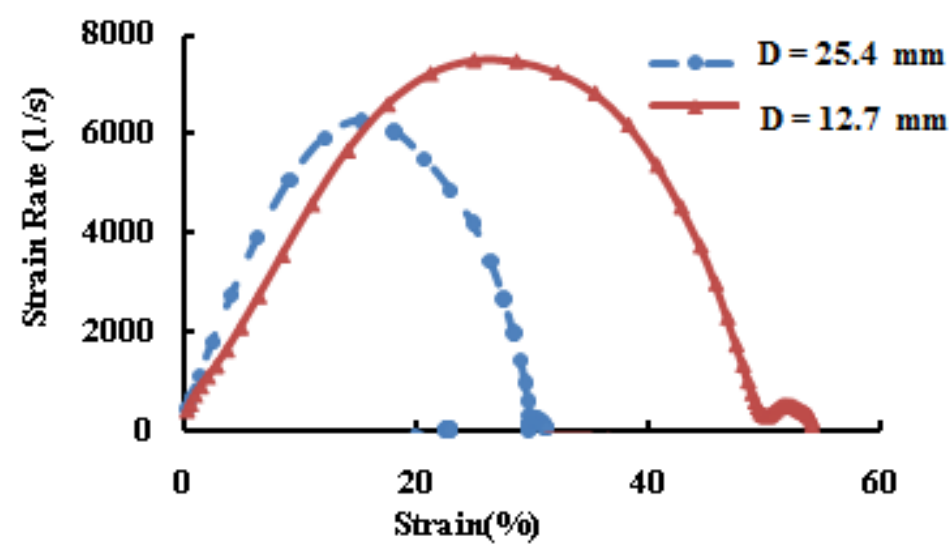

b)

Figure 13. Effect of the contact geometry on the strain rate - strain behavior of 8 ply (GW 8) specimens at a) $67 \mathrm{~J}$ and b) $163 \mathrm{~J}$ of impact energy 


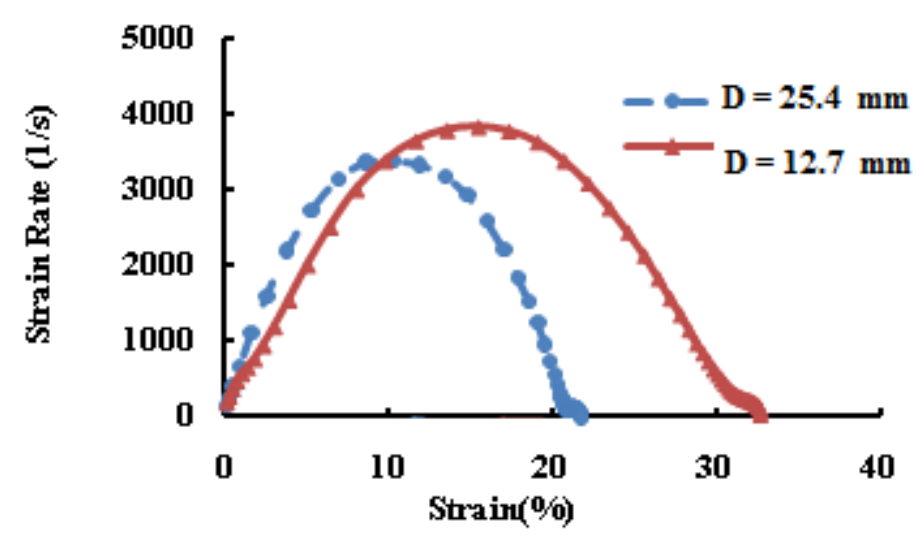

a)

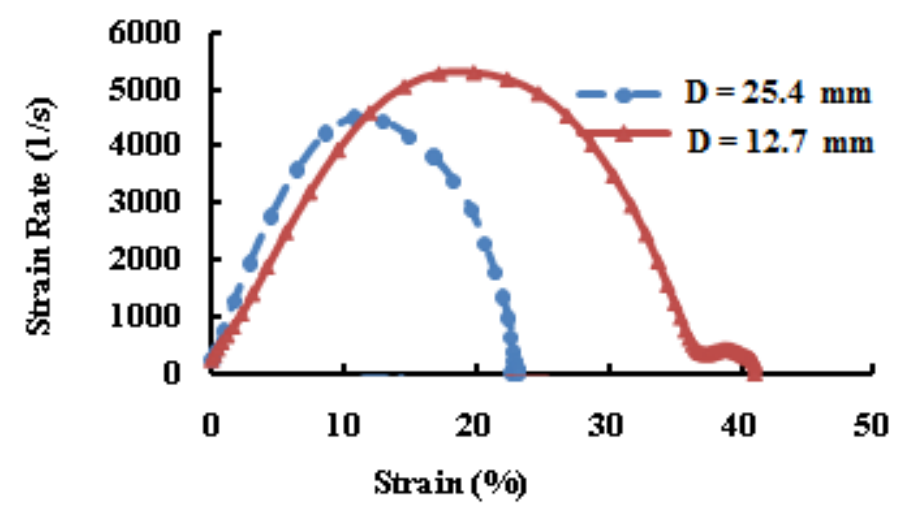

b)

Figure 14. Effect of the contact geometry on the strain rate - strain behavior of 12 ply (GW 12) specimens at a) $67 \mathrm{~J}$ and b) $163 \mathrm{~J}$ of impact energy 